\title{
Epidemiologic Study of Operative Treatment for Spinal Metastasis in Thailand : A Review of National Healthcare Data from 2005 to 2014
}

\author{
Panya Luksanapruksa, Borriwat Santipas, Monchai Ruangchainikom, Ekkapoj Korwutthikulrangsri, Witchate Pichaisak, \\ Sirichai Wilartratsami \\ Department of Orthopedic Surgery, Faculty of Medicine Siriraj Hospital, Mahidol University, Bangkok, Thailand
}

Objective : To study the factors relating to operative treatment for spinal metastasis in Thailand during 2005-2014 and to determine the hospital costs, mortality rate, and incidence of perioperative complication.

Methods : Inpatient reimbursement data from 2005 to 2014 was reviewed from three national healthcare organizations, including the National Health Security Office, the Social Security Office, and the Comptroller General's Department. The search criteria were secondary malignant neoplasm of bone and bone marrow patients (International Classification of Diseases 10th revision, Thai modification codes [ICD 10-TM], C79.5 and C79.8) who underwent spinal surgical treatment (ICD 9th revision, clinical modification procedure with extension codes [ICD 9-CM], 03.0, 03.4, 03.09, and 81.0) during 2005-2014. Epidemiology, comorbidity, and perioperative complication were analyzed.

Results : During the study period, the number of spinal metastasis patients who underwent operative treatment was significantly increased from 0.30 to 0.59 per $100000(p<0.001)$. More males $(56.14 \%)$ underwent surgical treatment for spinal metastasis than females. The most common age group was 45-64 (55.1\%). The most common primary tumor sites were the unknown origin, lung, breast, prostate, and hepatocellular/bile duct. Interestingly, the proportion of hepatocellular/bile duct, breast, and lung cancer was significantly increased $(p<0.001)$. The number of patients who had comorbidity or in-hospital complication significantly increased over time $(p<0.01)$; however, the in-hospital mortality rate decreased.

Conclusion : During the last decade, operative treatment for spinal metastasis increased in Thailand. The overall in-hospital complication rate increased; however, the in-hospital mortality rate decreased.

Key Words : Epidemiology · Surgical procedures · Spine, metastasis · Thailand · Trends.

\section{INTRODUCTION}

The spine is the most frequent site of bone metastasis. Approximately $50 \%$ of bony metastases involve the spine ${ }^{1)}$. Five to $30 \%$ of spinal metastasis patients develop spinal cord compression, and $8 \%$ present with spinal cord compression as the initial manifestation of cancer $^{4,10,12)}$. The most common clinical presentations are neurological deficit and axial spinal pain.

- Received : November 30, 2020 •Revised : March 23, 2021 •Accepted : April 7, 2021

- Address for reprints : Sirichai Wilartratsami

Department of Orthopedic Surgery, Faculty of Medicine Siriraj Hospital, Mahidol University, 2 Wanglang Road, Bangkoknoi, Bangkok 10700, Thailand

Tel : +66-2-419-7969, Fax : +66-2-419-7961, E-mail : sirichai_w@hotmail.com, ORCID : https://orcid.org/0000-0001-7651-4196

This is an Open Access article distributed under the terms of the Creative Commons Attribution Non-Commercial License (http://creativecommons.org/licenses/by-nc/4.0) which permits unrestricted non-commercial use, distribution, and reproduction in any medium, provided the original work is properly cited. 
The mainstay spinal metastasis treatments include chemotherapy, radiotherapy, and surgery. Surgery is one of the treatments of spinal metastases patients which can improve the quality of life of these patients compared with conservative treatment ${ }^{8,9)}$, especially in the patient with symptomatic spinal epidural compression ${ }^{3)}$.

The indications for surgery in spinal metastasis patients are progressive neurological deficit, spinal instability, and intractable pain. However, the decision whether to perform or not perform surgery is based on a cost-benefit analysis ${ }^{2)}$ that weighs the operation's risk against the patient's life expectan$\mathrm{cy}^{11)}$ and quality of life. Treatment options, including chemotherapy, radiation therapy, immunotherapy, and targeted therapy, continue to improve, and these treatments have prolonged survival in this patient population. The surgical techniques and instrumentation have also improved, which has resulted in an increasing population growth-adjusted rate of surgical treatment for this disease ${ }^{13)}$.

Many studies have reported postoperative complication ${ }^{6)}$ resulting from spinal metastasis in developed countries. However, no national epidemiologic study of spinal metastasis has been conducted in Southeast Asia.

Accordingly, the aim of this study was to investigate the factors relating to operative treatment for spinal metastasis in Thailand during 2005-2014 and to determine the hospital costs, mortality rate, length of hospital stay, and incidence of perioperative complication.

\section{MATERIALS AND METHODS}

This study was approved by the Siriraj Institutional Review Board (COA No. 168/2558 [EC3]). Patient data were collected from three major national healthcare organizations in Thailand that reimburse hospitals for incurred treatment costs. We analyzed hospital discharge records from 2005 to 2014 from the National Health Security Office, Social Security, and the Comptroller General's Department. These three entities account for $92.2 \%$ of all-payer inpatient data, and every entry represents a single hospitalization.

A retrospective database search was performed. The inclusion criteria were secondary malignant neoplasm of bone and bone marrow patients (International Classification of Diseases 10th revision, Thai modification codes [ICD 10-TM], C79.5 and C79.8) who underwent spinal surgical treatment (ICD 9th revision, clinical modification procedure with extension codes [ICD 9-CM], 03.0, 03.4, 03.09, and 81.0) during 2005-2014. The surgical treatment in this period including tumor removal, decompression of the spinal canal, and instrumentation of the spinal column. We cannot specify the surgical approach in each case due to the data were recorded as ICD 9-CM. Searchrelated details are shown in Table 1.

Data extracted included age at surgery, gender, type of hospital, site of the primary tumor, underlying disease, postoperative complications, discharge status, length of stay, and hospital charges. According to the system proposed by Yoshihara and Yoneoka ${ }^{13)}$, patients were classified into five groups, as follows : birth to 17 years, 18 to 44 years, 45 to 64 years, 65 to 84 years, and older than 84 years. The type of hospital was categorized into medical university hospital, regional hospital, general hospital, community hospital, and private hospital. Perioperative complications were obtained using the following ICD-10-TM codes : respiratory complications (J80, J81, J951, J952, J960, J984, J989); cardiac complications (I21, I51); urinary and renal complications (N39); neurologic complications (G96, G98, I63); thromboembolism (I26, I279, I740, I80, I82); gastrointestinal complications (K291, K720, K729, K810, K85, K92); and wound-related complications (T810, T813, T814).

We obtained Thai population data from the Department of

Table 1. List of the diagnostic criteria codes identify patients who underwent surgical treatment for spinal metastasis

\begin{tabular}{|c|c|}
\hline Code & Explanation \\
\hline \multicolumn{2}{|c|}{ ICD 10-TM } \\
\hline C79.5 & $\begin{array}{l}\text { Secondary malignant neoplasm of bone } \\
\text { and bone marrow }\end{array}$ \\
\hline C79.8 & $\begin{array}{l}\text { Secondary malignant neoplasm of other } \\
\text { specified sites }\end{array}$ \\
\hline \multicolumn{2}{|c|}{ ICD 9-CM procedure code } \\
\hline 03.0 & $\begin{array}{l}\text { Exploration and decompression of spinal } \\
\text { canal structures }\end{array}$ \\
\hline 03.4 & $\begin{array}{l}\text { Excision or destruction of lesion of spinal } \\
\text { cord or spinal meninges }\end{array}$ \\
\hline 03.09 & $\begin{array}{l}\text { Other exploration and decompression of } \\
\text { spinal canal }\end{array}$ \\
\hline 81.0 & Spinal fusion \\
\hline
\end{tabular}

ICD 10-TM : International Classification of Diseases 10th revision, Thai modification codes, ICD 9-CM : International Classification of Diseases 9th revision, clinical modification procedure with extension codes 
Provincial Administration website. Hospital charges were reported as the actual amount charged (Thai baht, THB), and those charges were adjusted for inflation using the consumer

Table 2. Patient demographic and clinical characteristics, and healthcare center data

\begin{tabular}{|c|c|}
\hline Characteristic & Value \\
\hline Total number of cases & 2702 \\
\hline Per 100000 & $0.30-0.59$ \\
\hline \multicolumn{2}{|l|}{ Patient age (years) } \\
\hline$<17$ & $14(0.51)$ \\
\hline $18-44$ & $398(14.72)$ \\
\hline $45-64$ & $1489(55.10)$ \\
\hline $65-84$ & 787 (29.12) \\
\hline$>85$ & $14(0.51)$ \\
\hline \multicolumn{2}{|l|}{ Gender } \\
\hline Male & $1517(56.14)$ \\
\hline Female & 1185 (43.86) \\
\hline \multicolumn{2}{|l|}{ Level of hospital } \\
\hline Medical school & $1236(45.74)$ \\
\hline Regional hospital & $609(22.53)$ \\
\hline General hospital & $686(25.38)$ \\
\hline Rural hospital & $16(0.59)$ \\
\hline Private hospital & $155(5.73)$ \\
\hline \multicolumn{2}{|l|}{ Hospital region } \\
\hline North & $198(7.32)$ \\
\hline Northeast & $630(23.31)$ \\
\hline East & $70(2.59)$ \\
\hline West & $31(1.14)$ \\
\hline South & $243(8.99)$ \\
\hline Central & $1530(56.62)$ \\
\hline \multicolumn{2}{|l|}{ Primary cancer } \\
\hline Unknown primary site & $365(13.60)$ \\
\hline Lung and bronchus cancer & $362(13.49)$ \\
\hline Breast cancer & $244(9.09)$ \\
\hline Prostate cancer & $203(7.56)$ \\
\hline $\begin{array}{l}\text { Hepatocellular carcinoma and } \\
\text { cholangiocarcinoma }\end{array}$ & $147(5.47)$ \\
\hline Thyroid cancer & $92(3.42)$ \\
\hline Cervix cancer & $85(3.17)$ \\
\hline Other cancer & $550(20.50)$ \\
\hline Not available & $635(23.67)$ \\
\hline
\end{tabular}

Values are presented as weighted frequency (\%) unless otherwise indicated price index from the year 2011 (THB). Conversion to US dollars (USD) was calculated using the exchange rate from January 2011 (30.5 THB = 1 USD).

\section{Data analysis}

Frequency and percentage were used to describe categorical data, and the mean and the range was used for continuous data. All analyses except for the chi-square test for trend were performed using SPSS Statistics version 18 (SPSS, Inc., Chicago, IL, USA). R program version 3.5.1 (free software foundation's GNU general public license) was used for the chi-square test for trend. The number of SM patients who underwent op-

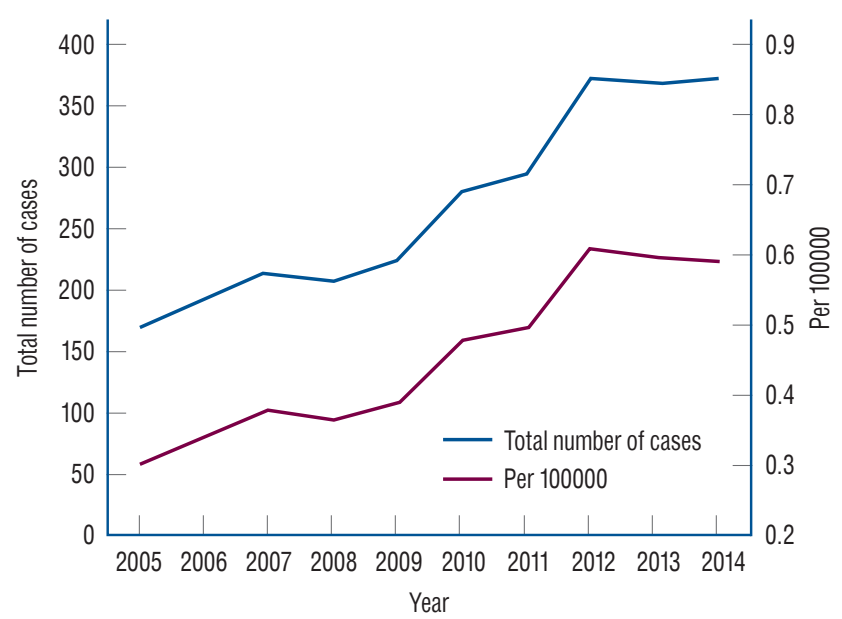

Fig. 1. The number and population growth-adjusted incidence rate of surgical treatment for spinal metastasis in Thailand from 2005 to 2014.

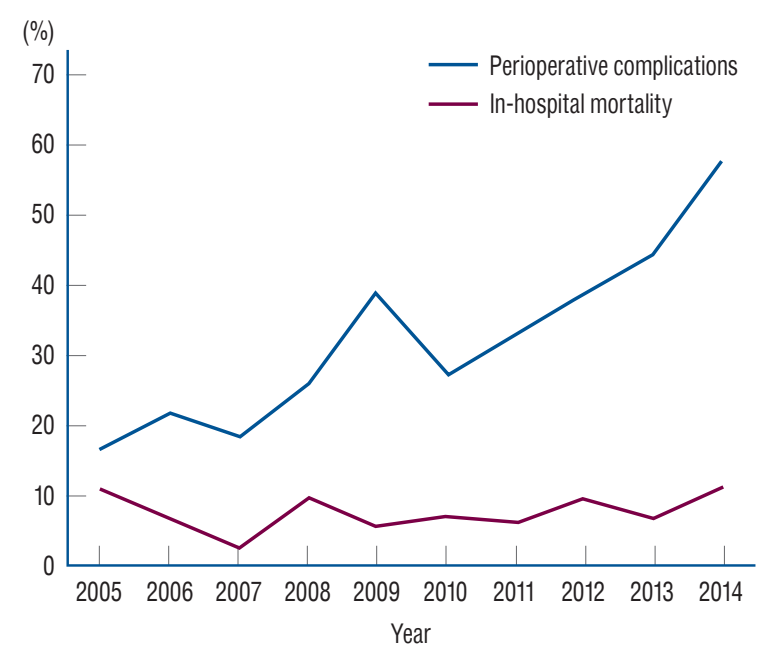

Fig. 2. Overall, in-hospital complication and mortality rates in patients who underwent surgical treatment for spinal metastasis in Thailand during 2005 to 2014 . 
erative treatment; the proportion of hepatocellular/bile duct, breast, and lung cancer; the number of patients with comorbidity; and the overall in-hospital complication rate were all analyzed using the chi-square test for trend. Chi-square test for trend was also used to test for a linear trend that an outcome increased or decreased over time. The linear regression

Table 3. Patient outcomes among patients who underwent surgical treatment for spinal metastasis

\begin{tabular}{lc}
\hline Outcome & Value \\
\hline Length of stay (days) & $30.80(27.93-39.01)$ \\
Mean hospital charge (Thai baht) & 174944.37 \\
Mortality rate (\%) & 7.7 \\
Complication & \\
Urinary and renal & $421(15.58)$ \\
Wound-related complications & $192(7.11)$ \\
Respiratory & $131(4.85)$ \\
Thromboembolism & $103(3.81)$ \\
Gastrointestinal & $63(2.33)$ \\
Cardiac & $26(0.96)$ \\
Neurologic & $16(0.59)$ \\
Overall complications & $952(35.23)$ \\
Weighted frequency & \\
Improved & $2380(88.08)$ \\
Not improved & $103(3.81)$ \\
Death & $208(7.69)$ \\
Not available & $11(0.40)$ \\
\hline
\end{tabular}

Values are presented as mean (range), number, or weighted frequency (\%)

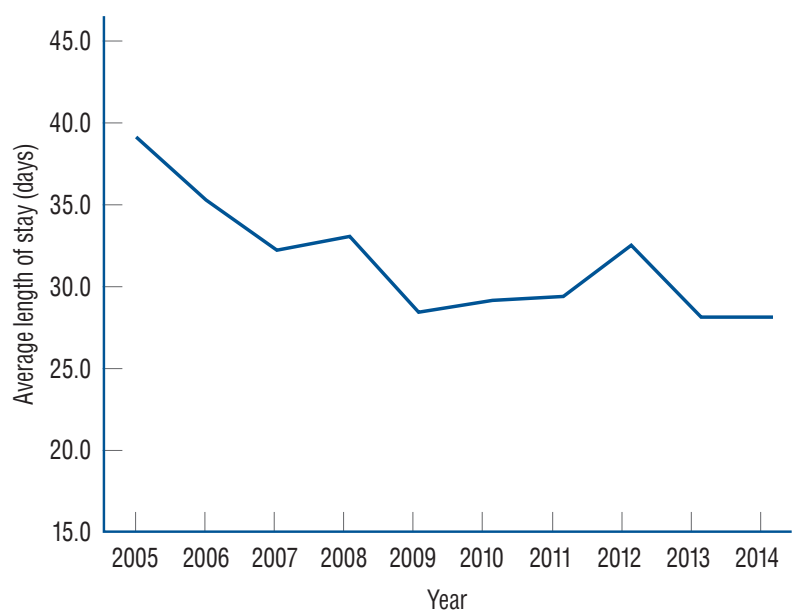

Fig. 3. The average length of hospital stays in patients who underwent surgical treatment for spinal metastasis in Thailand from 2005 to 2014. model analyzed in-hospital mortality and inflation-adjusted mean hospital charges. A $p$-value less than 0.05 was used to define a significant difference or trend.

\section{RESULTS}

During the years 2005-2014, a total of 2702 cases (1517 male patients [56.14\%] and 1185 female patients [43.86\%]) were included. The most common age groups were 45-64, 65-84, and 18-44 years. Most patients were operated upon at a medical school (45.74\%). The most common primary tumor sites were unknown origin (13.60\%), lung cancer (13.49\%), breast cancer (9.09\%), and prostate cancer (7.56\%). Patient demographic and clinical characteristics and treatment setting data are shown in Table 2. The annual number of patients who underwent surgical treatment increased substantially from 172 cases in 2005 to 372 cases in 2014. The population growth-adjusted rate also increased from 0.3 per 100000 in 2005 to 0.59 per 100000 in 2014 (Fig. 1).

The overall perioperative complication rate increased from $15.85 \%$ in 2005 to $60.68 \%$ in 2014 (Fig. 2). Perioperative complication rates during 2005 to 2014 were $15.58 \%$ for urinary and renal, $7.11 \%$ for wound-related, $4.85 \%$ for respiratory, $3.81 \%$ for thromboembolism, $2.33 \%$ for gastrointestinal, $0.96 \%$ for cardiac, $0.59 \%$ for neurologic, and $35.23 \%$ for overall complications (Table 3). The overall in-hospital mortality rate was $7.7 \%$, and the annual mortality rate was stable over

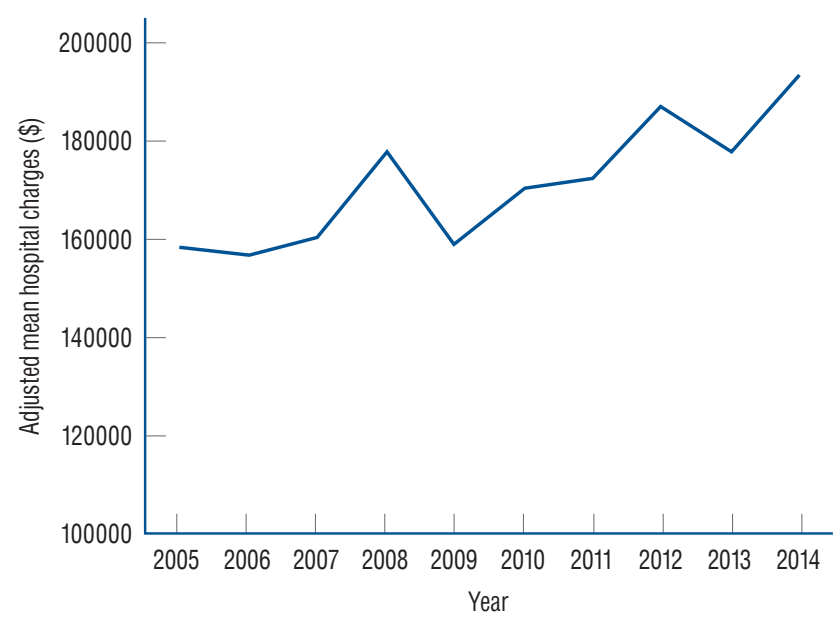

Fig. 4. Inflation-adjusted mean hospital charges in patients who underwent surgical treatment for spinal metastasis in Thailand during 2005 to 2014. 
time, from $11.05 \%$ in 2005 to $11.02 \%$ in 2014 (Fig. 2).

The total average length of stay was 30.8 days, with a decrease over time from 39.01 days in 2005 to 27.93 days in 2014 (Fig. 3). The inflation-adjusted mean hospital charges were 172137.18 THB (5456.74 USD, the conversion rate of 2011, which is the base year of consumer price index), with a significant increase over time from 158702.68 THB (3870.68 USD, conversion rate at the end of 2005) in 2005 to 193873.40 THB (5896.39 USD, conversion rate at the end of 2014) in 2014 $(p=0.001)$ (Fig. 4).

\section{DISCUSSION}

From 2005 to 2014, the number of spinal metastasis patients who underwent operative treatment was significantly increased from 0.30 to 0.59 per 100000 . The rate of surgery in Thailand was lower than during the same period in the USA (1.77 per 100000 in 2009). This type of surgery requires a welltrained spine surgeon and other supportive modalities, including a multidisciplinary team, spinal instrumentation, blood transfusion supply, and available intensive care units care. The requirements mentioned above suggest why the ratio of surgery in developing countries is lower than in developed countries. An increase in the volume of spinal metastasis surgeries may reflect improvements in spine care in a healthcare system; however, a similar increasing trend in spinal metastasis surgery was also observed in the USA (from 1.15 per
100000 in 2000 to 1.77 per 100000 in 2009).

Patil et al. ${ }^{7)}$ reviewed the United States National Inpatient Care Database (National Inpatient Sample). They reported the mortality rate and postoperative complication rate among spinal metastasis patients to be $5.6 \%$ and $21.9 \%$, respectively. The most common complications reported in that study were respiratory $(6.2 \%)$ and bleeding $(5.9 \%)^{7)}$, whereas the most common complication in this study was kidney/urinary/bladder (15.58\%). Moreover, the overall number of patients with inhospital complications significantly increased over time in our research. According to the increasing number of postoperative complications (Fig. 5), most of the complications were medical-related complications correlated with a rising number of patients who underwent surgery and their numerous underlying medical conditions (the detail of complication was shown in Table 3).

Yoshihara and Yoneoka ${ }^{13)}$ reported that the United States' mortality rate decreased from $5.2 \%$ to $4.6 \%$ during the years 2000-2009. The in-hospital mortality rate in the present study (7.7\%) was higher than in the Yoshihara and Yoneoka ${ }^{13)}$ study, but it was stable over time. Yoshihara and Yoneoka ${ }^{13)}$ also reported that hospital charges increased two-fold during their study period, while hospital charges in our study increased only $21.16 \%$ from 2005-2014.

Hsiue et al. ${ }^{5)}$ reported the number of metastatic spine diseases in the USA from 2010 to 2014, which increased 17\% in 5 years, and the mortality rate decreased from $4.8 \%$ to $4.2 \%$. The postoperative complications were stable over time.

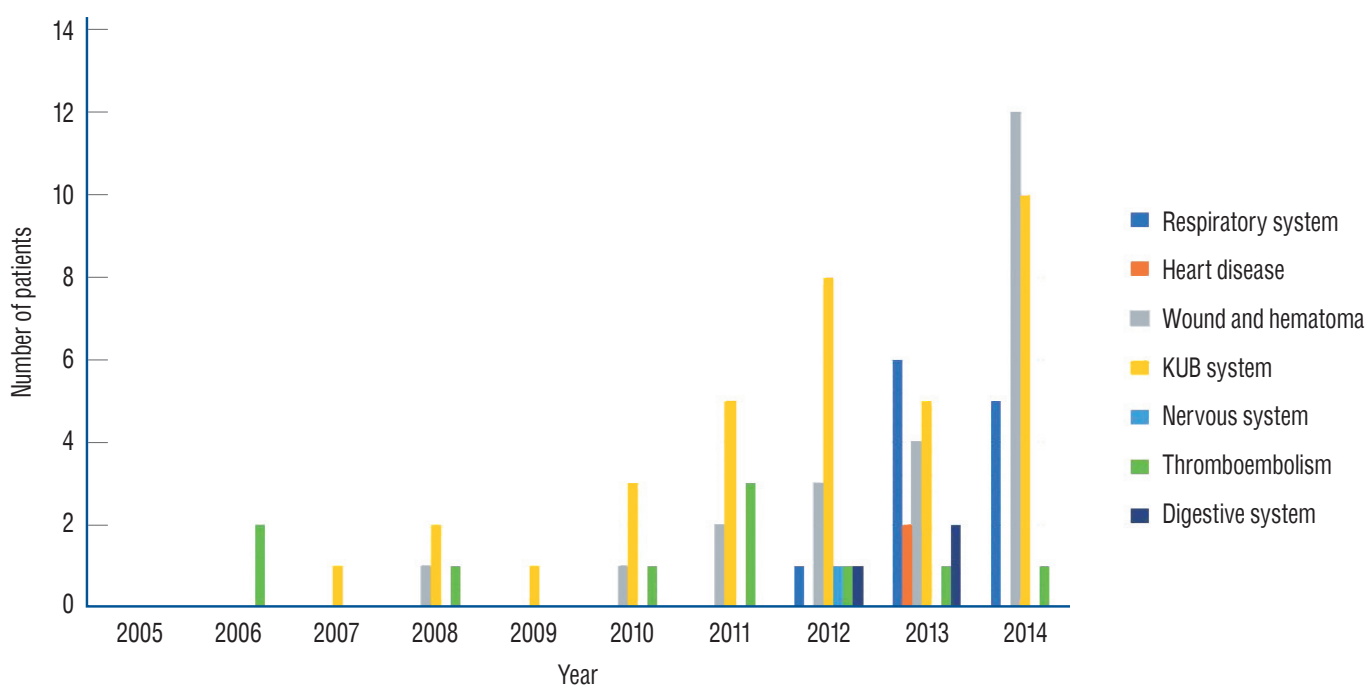

Fig. 5. Post-operative complication in year 2005-2014. KUB : kidney and urinary bladder. 


\section{Limitations}

Several factors limited this study. First, some data were not recorded in the discharge summary, such as primary tumor site, patient comorbidities, the surgical method or approaches, and some in-hospital complications, which may affect the surgical complication and costs differently in each type. Second, the actual hospital charges may not have been accurately reflected because the reimbursement schemes all have their scope of reimbursement. Third and last, our data does not include or reflect postoperative functional and neurological assessment, which is data that would be useful for evaluating the risk and benefit of surgery for this condition. This study's strength is that it is the first report to describe the national trend of surgical treatment for spinal metastasis patients in Southeast Asia over a recent 10-year period.

\section{CONCLUSION}

From 2005 to 2014, operative treatment for spinal metastasis increased in Thailand. The overall in-hospital complication rate increased; however, the in-hospital mortality rate decreased.

\section{CONFLICTS OF INTEREST}

No potential conflict of interest relevant to this article was reported.

\section{INFORMED CONSENT}

This type of study does not require informed consent.

\section{AUTHOR CONTRIBUTIONS}

Conceptualization : PL, WP, SW

Data curation : BS, EK

Methodology : BS, MR

Project administration : PL, SW

Writing - original draft : BS

Writing - review \& editing : PL, BS, MR, EK, WP, SW

\section{ORCID}

Panya Luksanapruksa https://orcid.org/0000-0002-9554-4259

Borriwat Santipas https://orcid.org/0000-0001-6804-6644

Monchai Ruangchainikom https://orcid.org/0000-0003-0525-6390

Ekkapoj Korwutthikulrangsri

https://orcid.org/0000-0003-0136-1046

Witchate Pichaisak https://orcid.org/0000-0002-8147-4544

Sirichai Wilartratsami https://orcid.org/0000-0001-7651-4196

\section{- Acknowledgements}

This study was funded by a grant from the faculty of Medicine, Mahidol University, Siriraj Hospital (grant no. R015832033).

The authors would like to thank Miss Nhathita Panatreswas for statistical analysis, editing the manuscript, and assisting with the journal submission process.

\section{References}

1. Aebi M : Spinal metastasis in the elderly. Eur Spine J 12 Suppl 2 : S202-S213, 2003

2. Fehlings MG, Nater $A$, Holmer $H$ : Cost-effectiveness of surgery in the management of metastatic epidural spinal cord compression: a systematic review. Spine (Phila Pa 1976) 39 : S99-S105, 2014

3. Fehlings MG, Nater A, Tetreault L, Kopjar B, Arnold P, Dekutoski M, et al. : Survival and clinical outcomes in surgically treated patients with metastatic epidural spinal cord compression: results of the prospective multicenter AOSpine study. J Clin Oncol 34 : 268-276, 2016

4. Horn SR, Dhillon ES, Poorman GW, Tishelman JC, Segreto FA, Bortz $C A$, et al. : Epidemiology and national trends in prevalence and surgical management of metastatic spinal disease. J Clin Neurosci 53 : 183187,2018

5. Hsiue PP, Kelley BV, Chen CJ, Stavrakis Al, Lord EL, Shamie AN, et al. : Surgical treatment of metastatic spine disease: an update on national trends and clinical outcomes from 2010 to 2014. Spine J 20 : 915-924, 2020

6. Luksanapruksa P, Buchowski JM, Zebala LP, Kepler CK, Singhatanadgige W, Bumpass DB : Perioperative complications of spinal metastases surgery. Clin Spine Surg $30:$ 4-13, 2017

7. Patil CG, Lad SP, Santarelli J, Boakye M : National inpatient complications and outcomes after surgery for spinal metastasis from 1993-2002. Cancer $110: 625-630,2007$

8. Schoenfeld AJ, Losina E, Ferrone ML, Schwab JH, Chi JH, Blucher JA, et al. : Ambulatory status after surgical and nonsurgical treatment for spinal metastasis. Cancer 125 : 2631-2637, 2019

9. Schoenfeld AJ, Schwab JH, Ferrone ML, Blucher JA, Balboni TA, Barton 
National Trend of Spinal Metastasis | Luksanapruksa P, et al.

LB, et al. : Non-operative management of spinal metastases: a prognostic model for failure. Clin Neurol Neurosurg 188 : 105574, 2020

10. Siegal $T$, Siegal $T$ : Current considerations in the management of neoplastic spinal cord compression. Spine (Phila Pa 1976) 14 : 223-228, 1989

11. Tokuhashi Y, Matsuzaki H, Oda H, Oshima M, Ryu J : A revised scoring system for preoperative evaluation of metastatic spine tumor prognosis. Spine (Phila Pa 1976) 30 : 2186-2191, 2005
12. Wright E, Ricciardi F, Arts M, Buchowski JM, Chung CK, Coppes M, et al. : Metastatic spine tumor epidemiology: comparison of trends in surgery across two decades and three continents. World Neurosurg 114 : e809-e817, 2018

13. Yoshihara $\mathrm{H}$, Yoneoka $\mathrm{D}$ : Trends in the surgical treatment for spinal metastasis and the in-hospital patient outcomes in the United States from 2000 to 2009. Spine J 14 : 1844-1849, 2014 